Departement für Kleintiere, Klinik für Kleintierchirurgie, Abteilung Neurologie der Vetsuisse-Fakultät Universität Zürich

Direktor a. i.: Prof. Dr. P. R. Kircher, PhD, DECVDI

Arbeit unter wissenschaftlicher Betreuung von

PD Dr. med. vet. Frank Steffen DECVN

\title{
Radiographic and MRI characteristics of lumbar disseminated idiopathic spinal hyperostosis and spondylosis deformans in dogs.
}

\author{
Inaugural-Dissertation \\ zur Erlangung der Doktorwürde der \\ Vetsuisse-Fakultät Universität Zürich \\ vorgelegt von

\section{Andrea Giovanni Togni} \\ Tierarzt \\ von Brione/Verzasca, Ticino \\ genehmigt auf Antrag von \\ PD Dr. med. vet. Frank Steffen DECVN
}




\section{Inhaltsverzeichnis}

Abstract English

S. 1

Zusammenfassung Deutsch

S. 2

Artikel

"Radiographic and MRI characteristics of

lumbar disseminated idiopathic spinal hyperostosis

and spondylosis deformans in dogs."

Accepted for publication on 19.2.2014,

DOI: $10.1111 /$ jsap. 12218

\section{Danksagung}

Lebenslauf
S. $3-20$ 
Vetsuisse-Fakultät Universität Zürich (2014)

Andrea Togni

Kleintierchirurgie Abteilung Neurologie, cderobillard@vetclinics.uzh.ch

\section{Radiographic and MRI characteristics of lumbar disseminated idiopathic spinal hyperostosis and spondylosis deformans in dogs.}

Objective: To evaluate clinical signs, describe lesions and differences in the magnetic resonance imaging appearance of spinal new bone formations classified as disseminated idiopathic spinal hyperostosis and/or spondylosis deformans on radiographs and compare degeneration status of the intervertebral discs using the Pfirrmann scale.

Methods: Retrospective analysis of 18 dogs presented with spinal disorders using information from radiographic and magnetic resonance imaging (MRI) examinations. Results: All dogs were found to be affected with both disseminated idiopathic spinal hyperostosis and spondylosis deformans. Neurological signs due to foraminal stenosis associated with disseminated idiopathic spinal hyperostosis were found in two dogs. Spondylosis deformans was associated with foraminal stenosis and/or disc protrusion in 15 cases. The Pfirrmann score on MRI was significantly higher in spondylosis deformans compared with disseminated idiopathic spinal hyperostosis and signal intensity of new bone due to disseminated idiopathic spinal hyperostosis was significantly higher compared to spondylosis deformans.

Conclusion: Differences between disseminated idiopathic spinal hyperostosis and spondylosis deformans found on MRI contribute to an increased differentiation between the two entities. Clinically relevant lesions in association with disseminated idiopathic spinal hyperostosis were rare compared to those seen with spondylosis deformans.

Keywords

[Dog, spine, DISH, spondylosis] 


\section{Radiographic and MRI characteristics of lumbar disseminated idiopathic spinal hyperostosis and spondylosis deformans in dogs.}

Die Ziele dieser retrospektiven Arbeit beinhalteten die Untersuchung der klinischen Beschwerden im Zusammenhang mit Knochenneubildungen unterschiedlicher Aetiologie (DISH und SD) an der Lendenwirbelsäule von Hunden. Weiter wurden, ausgehend von Röntgenaufnahmen, die MRT Charakteristika der beiden Krankheiten beschrieben und verglichen. Das Degenerationsstadium der Bandscheiben wurde mit Hilfe der Pfirrrmann Skala bestimmt.

Das Patientengut bestand aus 18 Hunden mit klinischen Beschwerden, die durch Läsionen an der Lendenwirbelsäule hervorgerufen wurden und bei denen sowohl radiologische als auch magnetresonanztomographische Untersuchungen dieses Wirbelsäulenabschnitts vorlagen. Bei allen Patienten fanden sich beide Formen von Knochenneubildungen. Bei 2 Hunden wurden die neurologischen Probleme durch foraminale Stenosen infolge von DISH verursacht. Bei 15 Tieren wurden Diskushernien und foraminale Stenosen im Zusammenhang mit SD gefunden. Der Degenerationszustand der Bandscheiben - ausgedrückt durch den Pfirrmann Grad - war bei SD signifikant höher als bei DISH. Die Signalintensität des neu gebildeten Knochens war bei DISH signifikant höher als bei SD.

Die Magnetresonanztomographie liefert bei der bildgebenden Diagnostik von DISH und SD zusätzliche Informationen, die bei der Unterscheidung der beiden Erkrankungen hilfreich sind. Klinisch relevante Läsionen sind bei DISH im Unterschied zu SD selten.

Schlüsselwörter

[Hund, Wirbelsäule, DISH, Spondylose] 


\title{
Radiographic and MRI characteristics of lumbar disseminated idiopathic spinal hyperostosis and spondylosis deformans in dogs.
}

\author{
A.Togni*, H. J. C. Kranenburg†, J. P. Morgan† and F. Steffen* \\ *Clinic for Small Animal Surgery, Surgery/Section of Neurology, Vetsuisse Faculty University of Zurich, Zurich, \\ Switzerland \\ $\dagger$ Department of Clinical Sciences of Companion Animals, Faculty of Veterinary Medicine, Utrecht University, \\ Utrecht, The \\ Netherlands \\ \$Division of Diagnostic Imaging, Vetsuisse Faculty,University of Zurich, Switzerland
}

\section{Introduction}

Diffuse idiopathic skeletal hyperostosis (DISH) and spondylosis deformans (SD) are thought to represent two different types of spinal new bone formation that occur in dogs (Morgan \& Stavenborn 1991; H.-J. C. Kranenburg et al. 2011; Woodard et al. 1985). DISH is a systemic non-inflammatory disorder, with the principal manifestation being ossification of soft tissues such as ligaments and attachments of tendons and capsules to bone (enthesis). DISH in dogs is mostly characterized by generalized new bone formation that appears as flowing ossification due to their trabecular pattern, along the ventral and lateral aspects of the vertebral column (Woodard et al. 1985; H.-J. C. Kranenburg et al. 2011). The intervertebral disc (IVD) width is preserved (Ortega et al. 2012), and the vertebral endplates are not affected. Canine DISH has been proposed as a spontaneous model for the disorder in humans (Larsen \& Selby 1981; Eichelberg \& Wurster 1982; H. C. Kranenburg et al. 2010). The aetiology of canine DISH is unknown, but a hereditary basis has been suggested for boxers (Langeland \& Lingaas 1995). Another hypothesis suggests that canine DISH may be secondary to other diseases including hypoparathyroidism and hypercalcitonism (Morgan \& Stavenborn 1991). In humans, various metabolic, endocrinological, genetic and environmental factors have been suspected to contribute to its development (Cammisa et al. 1998; Kiss et al. 2002; Mata et al. 1997). DISH is suspected to cause spinal pain and 
dysfunction (H.-J. C. Kranenburg et al. 2011), but clinical significance of the disorder is difficult to ascertain because the new bone formation is also found in asymptomatic dogs.

$\mathrm{SD}$ is characterized by more focal vertebral osteophytes, varying from small osteophytes to larger spurs, which appear to attempt to bridge an intervertebral disc space. Degeneration of the IVD was initially thought to be a prerequisite for SD but radiographic studies demonstrated that discs without degenerative changes are also found in combination with SD (Morgan et al. 1985; Levine et al. 2006). In more recent studies using magnetic resonance imaging (MRI) and radiographs it was found that combining both modalities correlated best with morphological and biochemical degrees of disc degeneration (Benneker et al. 2005).

Like DISH, SD is a non-inflammatory disorder, which is not considered to be of great clinical relevance. However, stiffness of the back, lameness, changes in gait, and pain have been described and there is a possible association with disc protrusion (Morgan et al. 1989; Morgan et al. 1967; Carnier et al. 2004; Levine et al. 2006; Westerveld et al. 2009; Verlaan et al. 2011; Belanger \& Rowe 2001; Olivieri et al. 2007).

In earlier reports DISH and SD were often not specifically separated (Morgan et al. 1967; Langeland \& Lingaas 1995; Morgan et al. 1989; Carnier et al. 2004). One explanation may be that radiographic differentiation has been stated as difficult in severe cases of canine and human spinal new bone formations (Levine et al. 2006; H.-J. C. Kranenburg et al. 2011; Resnick \& Niwayama 1976). Furthermore, as both conditions may present without radiographic signs of disc degeneration, it can be difficult to differentiate SD and DISH based on radiographic interpretation alone. Therefore, MRI assessment including sensitive grading of disc degeneration may allow a more accurate separation between the two entities. The 
Pfirrmann grading scale (grade 1 to 5) has been used to classify degenerative changes of the IVD in humans (Pfirrmann et al. 2001) and dogs (Bergknut et al. 2011) and represents a valuable tool for this purpose. The 5-category scale has been created to quantify the degree of disc degeneration on the basis of sagittal T2-weighted MRI (Table 1). The principal criteria to grade the discs include assessment of structure and intensity of the nucleus pulposus and its distinction from the annulus fibrosus. Additionally, the intervertebral disc width is part of the final scoring.

Our goal was to describe radiographic and MRI-findings including degeneration status of the IVD using the Pfirrmann scale in vertebral segments with new bone formations in order to allow a more precise differentiation between DISH and SD.

Table 1. Classification of disc degeneration in MRI (Pfirrmann et al. 2001)

\begin{tabular}{|l|l|l|l|l|}
\hline Grade & Structure & $\begin{array}{l}\text { Distinction of } \\
\text { nucleus and } \\
\text { annulus }\end{array}$ & Signal intensity & $\begin{array}{l}\text { Height of } \\
\text { intervertebral } \\
\text { disc }\end{array}$ \\
\hline I & $\begin{array}{l}\text { Homogeneous, } \\
\text { bright white }\end{array}$ & Clear & $\begin{array}{l}\text { Hyperintense, } \\
\text { isointense to } \\
\text { cerebrospinal } \\
\text { fluid }\end{array}$ & Normal \\
\hline II & $\begin{array}{l}\text { Inhomogeneous } \\
\text { with or without } \\
\text { horizontal bands }\end{array}$ & Clear & $\begin{array}{l}\text { Hyperintense, } \\
\text { isointense to } \\
\text { cerebrospinal } \\
\text { fluid }\end{array}$ & Normal \\
\hline III & $\begin{array}{l}\text { Inhomogeneous, } \\
\text { grey }\end{array}$ & $\begin{array}{l}\text { Intermediate } \\
\text { Inclear }\end{array}$ & $\begin{array}{l}\text { Normal to } \\
\text { slightly } \\
\text { decreased }\end{array}$ \\
\hline IV & Inhomogeneous, \\
grey to black & $\begin{array}{l}\text { Lost } \\
\text { black }\end{array}$ & $\begin{array}{l}\text { Intermediate to } \\
\text { hypointense }\end{array}$ & $\begin{array}{l}\text { Normal to } \\
\text { moderately } \\
\text { decreased }\end{array}$ \\
\hline V & Homogeneous, & Lost & Hypointense & $\begin{array}{l}\text { Collapsed disc } \\
\text { space }\end{array}$ \\
\hline
\end{tabular}




\section{Material and Methods}

Dogs

Medical records of dogs presented to the neurology section of the Vetsuisse faculty of the University of Zurich and diagnosed radiographically with lumbar DISH and clinical signs of spinal hyperaesthesia, lameness or spinal cord dysfunction between 2005 and 2010 were retrospectively reviewed. Dogs referred to the neurological service due to spinal disease were included if information of both radiographic and MRI was available for at least vertebral segments L2 to S1. A vertebral segment consists of 2 vertebral bodies, a pair of facet joints, the intervertebral disc and all adjoining ligaments between them. Dogs with concurrent orthopaedic conditions were excluded. Recorded information included breed, age, gender, physical, orthopaedic and neurological examinations, blood work, treatment and follow-up.

\section{Diagnostic imaging}

Imaging procedures were obtained with the dogs under general anaesthesia. After premedication with medetomidine (10 $\mu \mathrm{g} / \mathrm{kg}$ intravenously (IV), Rimadyl; Pfizer) and butorphanol (0.2mg/kg IV, Temgesic; Reckitt Benckiser) anesthesia was induced with propofol (4mg/kg IV, Propofol 1\% MTC; Fresenius Kabi) and maintained with isoflurane (Isofluoran; Baxter) in oxygen.

A minimum of two radiographic views of the spine caudal to L2 were taken for all dogs in lateral and dorsal recumbency. Radiographs were examined by a board-certified radiologist (JPM) for presence of DISH and SD.

The diagnosis of DISH was based on radiographic criteria as earlier postulated by others: a) flowing calcification and ossification along the ventral aspect of at least three 
(Morgan \& Stavenborn 1991; Rogers \& Waldron 2001) or four contiguous vertebral bodies. For the purpose of this investigation, dogs were included when at least three vertebral bodies were involved, b) relative preservation of the disc space width within involved areas and absence of degenerative disc disease on radiographs (Langeland \& Lingaas 1995; Morgan \& Stavenborn 1991). In this study, there was a focus on the spinal alterations of DISH only because radiographs of pelvis and appendicular skeleton were not available. Diagnostic imaging criteria for SD were as follows: a) vertebral osteophytes arising from the periphery of the end-plate, b) preservation of the ventral cortex of the affected segment; c) sclerotic end plates (H.-J. C. Kranenburg et al. 2011; Morgan et al. 1985; Resnick \& Niwayama 1976).

On radiographs, affected vertebral segments were counted and a ratio (vertebral thickness ratio) of the sagittal height of the vertebral body affected with DISH including the new bone formation (measured in the midline of the vertebral body) to the sagittal height of L7 of the same patient was recorded. Vertebra L7 (measured at the point with the lowest diameter of the vertebral body) was chosen as reference because in this vertebra the ventral contour was not obscured by new bone in all cases of the present investigation. The number and sites of vertebral segments with SD were recorded. The degree of severity of SD was graded according to the scale used by Langeland and Lingaas (1995). The 3-category system divided SD into grades 1 (presence of bony spurs), 2 (ossification cores between vertebral bodies) and 3 (complete ventral bridging of the intervertebral space).

MRI of the entire lumbar and sacral, plus the caudal portion of the thoracic spine (Th 10-13) was performed in all dogs using a 1.5 Tesla magnet with a spine array coil. The dogs were positioned in dorsal recumbency with the pelvic limbs extended. Standard fast spin echo (FSE) sequences were used. Settings included sagittal T2-weighted images (repetition time (TR) 3720-4000ms, echo time (TE) 108-123ms, field of view (FOV) 
300-320mm, slice thickness 2mm, and 2-3 acquisitions) and sagittal T1-weighted images (TR 550-672ms, TE 12-15ms; FOV 240-320mm, slice thickness 2mm, and 2-3 acquisitions). Transverse images were obtained parallel to the intervertebral disc space and were T2weighted in all cases (TR 4000-6360ms, TE 110-120 ms, FOV 180-220mm, slice thickness 2mm, and 3-4 acquisitions). Short-tau inversion recovery (STIR) sagittal sequences were performed.

The images were exported to a workstation (OsiriX v.4.1. 64-bit, DICOM Viewer. See www.osirix-viewer.com). The signal intensity (SI) of the new bone due to DISH and SD was measured on sagittal T2W-images at the level of the IVD and endplates. An oval region including most of the area of new bone proliferation was selected and intensity was measured. With the following index, the SI of the new bone was objectified in comparison with subcutaneous fat.

$$
\text { SI-index }(\mathrm{SIx})=\frac{\text { SI (subcutaneous fat) }-\mathrm{SI} \text { (new bone) }}{\mathrm{-SI}(\text { subcutaneous fat) }}
$$

Subcutaneous fat was chosen as reference because it has a constant appearance among the various tissues.

The resulting SIx allowed comparison within the same dog and also between the various patients because it corrects inevitable differences that occur in different MRI examinations. In general, the lower the value of SIx the more hyperintense the new bone. 
MRI images were interpreted by a board-certified neurologist or a board-certified radiologist and the lesion responsible for the clinical signs was identified. In addition, the Pfirrmann grade was assessed in sagittal T2-weighted images (Bergknut et al. 2011).

\section{Treatment and Outcome}

Based upon their clinical signs and MRI findings dogs were treated medically or surgically (Table 2). A board-certified neurologist performed follow-up examinations. Outcome was considered as excellent when clinical signs resolved completely. Good outcome was noted, when clinical signs improved but did not resolve completely. Outcome was satisfactory when spinal pain resolved but neurological signs did not improve. Outcome was poor when no improvement of clinical signs and persistent pain were found.

\section{Statistical analysis}

In order to evaluate if there was a statistically significant difference between the Pfirrmann grade of dogs with DISH versus dogs with SD, the AIC (Akaike information criterion) metric was used to choose the optimal mixed model for the data (Burnham 2004). This model was designed excluding normal vertebral segments and segments with characteristics of both DISH and SD in order to reduce the confounding factors. A linear mixed model was performed treating the response variable as a number and modeling the mean Pfirrmann score in the different treatment groups after accounting for the correlated effects of each dog. A two-sample student's t-test was used to objectify the SIx differences between new bone due to SD and DISH. 


\section{Results}

\section{Signalment}

Eighteen dogs were included. Breeds included boxer $(n=7)$, golden retriever $(n=3)$, flat coated retrievers $(n=2)$, and one each of, English cocker spaniel, Entlebucher mountain dog, Gordon setter, great Dane, Landseer, and mixed-breed. There was a predilection for female dogs (13 female spayed, 4 female intact and 1 male intact dog). Median age was 5.8 years (range 1.5 to 10 years). Median weight was $31.0 \mathrm{~kg}$ (range 13-60 kg).

\section{Clinical findings}

All dogs were found to have back pain, signs of thoracolumbar or lumbar spinal cord dysfunction and/or nerve root signs of different degrees of severity and at various levels (Table 2). Hematology and blood chemistry did not reveal any abnormalities.

SD was associated with clinical signs in 14 dogs. In comparison, DISH was thought to be the cause for the clinical signs in 2 dogs due to foraminal stenosis. Two dogs had discospondylitis.

\section{Radiographic findings}

One hundred of 108 vertebral segments (6 lumbar segments x 18 dogs) in 18 dogs were affected with spinal new bone formations based upon radiographs (Fig. 1). 


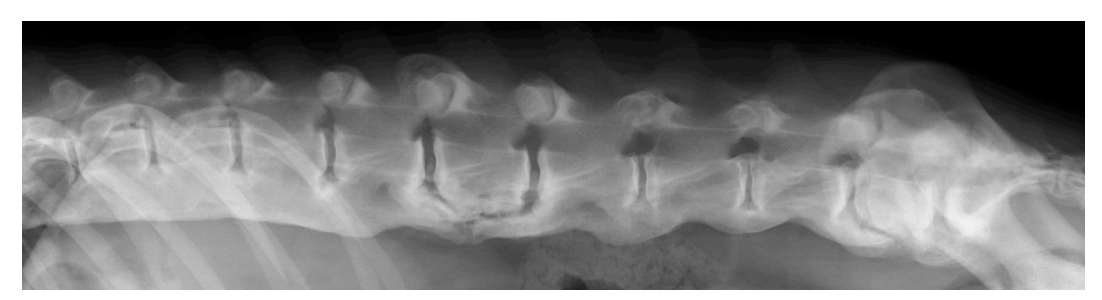

Figure 1. Laterolateral radiograph of case 8. Disseminated idiopathic spinal hyperostosis (DISH) is present between the $11^{\text {th }}$ thoracic and $2^{\text {nd }}$ lumbar $(\mathrm{L})$ and between the $4^{\text {th }}$ and $6^{\text {th }} \mathrm{L}$ vertebrae. Spondylosis deformans (SD) can be appreciated between the $2^{\text {nd }}$ and $4^{\text {th }} \mathrm{L}$ vertebrae and the $6^{\text {th }} \mathrm{L}$ and first sacral vertebrae.

Forty-eight vertebral segments in 18 dogs were classified to be affected with DISH. DISH was found most frequently at vertebral bodies L5-L6 (14 /18 dogs). The number of vertebral segments per dog affected by DISH varied between 2 and 5 (Table 3). Overall, the mean number of affected vertebral bodies per dog was 3.66. Mean lateral heights of vertebral bodies affected with DISH were 1.5 (range 1.13 to 1.9 ) times larger in dimension than the height of L7.

Table 3. Distribution of disseminated idiopathic spinal hyperostosis affected segments in each dog.

\begin{tabular}{|r|c|c|c|c|c|c|}
\hline Segments & L2-3 & L3-4 & L4-5 & L5-6 & L6-7 & L7-S1 \\
\hline Dog 1 & $\mathrm{x}$ & & $\mathrm{x}$ & $\mathrm{x}$ & $\mathrm{x}$ & \\
$\operatorname{Dog} 2$ & & & $\mathrm{x}$ & $\mathrm{x}$ & & \\
$\operatorname{Dog} 3$ & & & & $\mathrm{x}$ & $\mathrm{x}$ & \\
$\operatorname{Dog} 4$ & & & & $\mathrm{x}$ & $\mathrm{x}$ & \\
$\operatorname{Dog} 5$ & & $\mathrm{x}$ & $\mathrm{x}$ & $\mathrm{x}$ & $\mathrm{x}$ & \\
$\operatorname{Dog} 6$ & & & & $\mathrm{x}$ & $\mathrm{x}$ & \\
$\operatorname{Dog} 7$ & $\mathrm{x}$ & $\mathrm{x}$ & $\mathrm{x}$ & $\mathrm{x}$ & $\mathrm{x}$ & \\
$\operatorname{Dog} 8$ & & & $\mathrm{x}$ & $\mathrm{x}$ & & \\
$\operatorname{Dog} 9$ & $\mathrm{x}$ & $\mathrm{x}$ & & & & \\
$\operatorname{Dog} 10$ & & & & $\mathrm{x}$ & $\mathrm{x}$ & \\
$\operatorname{Dog} 11$ & $\mathrm{x}$ & & $\mathrm{x}$ & $\mathrm{x}$ & $\mathrm{x}$ & \\
$\operatorname{Dog} 12$ & $\mathrm{x}$ & $\mathrm{x}$ & $\mathrm{x}$ & $\mathrm{x}$ & & \\
$\operatorname{Dog} 13$ & & & & $\mathrm{x}$ & $\mathrm{x}$ & \\
$\operatorname{Dog} 14$ & $\mathrm{x}$ & $\mathrm{x}$ & & & & \\
$\operatorname{Dog} 15$ & & $\mathrm{x}$ & $\mathrm{x}$ & & & \\
$\operatorname{Dog} 16$ & & $\mathrm{x}$ & $\mathrm{x}$ & & & \\
$\operatorname{Dog} 17$ & & & $\mathrm{x}$ & $\mathrm{x}$ & & \\
$\operatorname{Dog} 18$ & & & $\mathrm{x}$ & $\mathrm{x}$ & $\mathrm{x}$ & \\
\hline
\end{tabular}


A total of 33 vertebral segments affected with SD were identified in 18 dogs.

Osteophytes related to SD were most frequently noted to only project into the peridiscal tissue. The osteophytes were centered around the disc space rather than below the complete vertebral body as in DISH, and each adjacent lesion appeared to be a separate entity. In the lumbar vertebral column, the sites most frequently affected with SD were L7-S1 (18/18) followed by L2-L3 and L3-L4 (both 6/18). Six vertebral segments with SD were graded as 1, 24 as grade 2 and 3 as grade 3.

Fourteen of 18 dogs showed radiographic signs of SD adjacent to vertebral segments affected with DISH.

In 19 vertebral segments of 12 dogs the new bone formation could not be clearly attributed to DISH or SD.

\section{Magnetic resonance findings}

Eleven dogs had unilateral foraminal stenosis because of new bone formation affecting the exit zone of the intervertebral foramen. Five dogs had a protruding disc affecting the spinal segment adjacent to a DISH-segment. Two dogs had discospondylitis cranially to a DISH segment; in both cases, this was not diagnosed on radiographs (Table 2). Vertebral segments with DISH had a lower degree of intervertebral disc degeneration, as depicted in the Pfirrmann score (mean 1.5), compared to segments with SD (mean 2.87), the difference was statistically significant $(P<0.0001)$.

In vertebral segments affected with DISH, the 'T1- and T2-weighted' signal from vertebral bone marrow and new bone was of equal intensity in all cases on visual assessment. 
In comparison, in dogs with SD the signal from osteophytes was hypointense compared to the bone marrow signal on both 'T1- and T2-weighted' images. The hypointense signal from osteophytes extended into the area adjacent to the endplates in 11 dogs (Fig. 2). Comparison between the SIx of the new bone formation in vertebral segments affected with DISH (mean $0.6)$ and SD (mean 0.81$)$ revealed a statistically significant difference $(P=0.004)$.

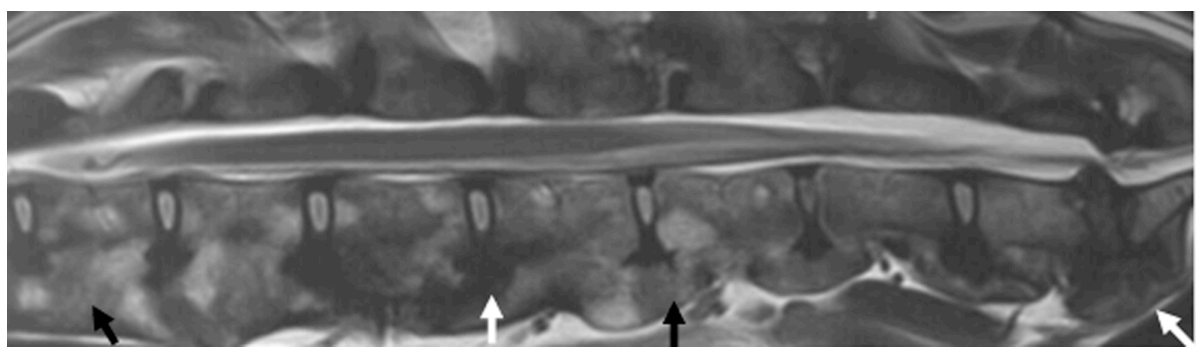

Figure 2. Sagittal T2-weigthed MRI (L1-S1) of case 8. New bone formations due to DISH (black arrows) are present between L1-2 and L4-6; new bone formations due to SD (white arrows) were found between L2-4 and L6-S1. Note differences in signal intensity of the bone marrow of segments affected with DISH and segments affected with SD.

MRI-characteristics of vertebral segments that could not be attributed to either DISH or SD based upon their radiographic appearance included a lower Pfirrmann grade (mean 1.63) compared to segments with SD (mean 2.87). Secondly, signal intensity of new bone had large areas of hypointensity on 'T1- and T2-weighted' images and STIR sequences; this indicates that no fat is contained within the new bone of these vertebral segments.

\section{Treatment and Outcome}

Surgical treatment was performed on 17 vertebral segments in 14 dogs. Details of surgical and conservative treatment, outcome and follow-up results of 18 cases are reported in table 2 . 


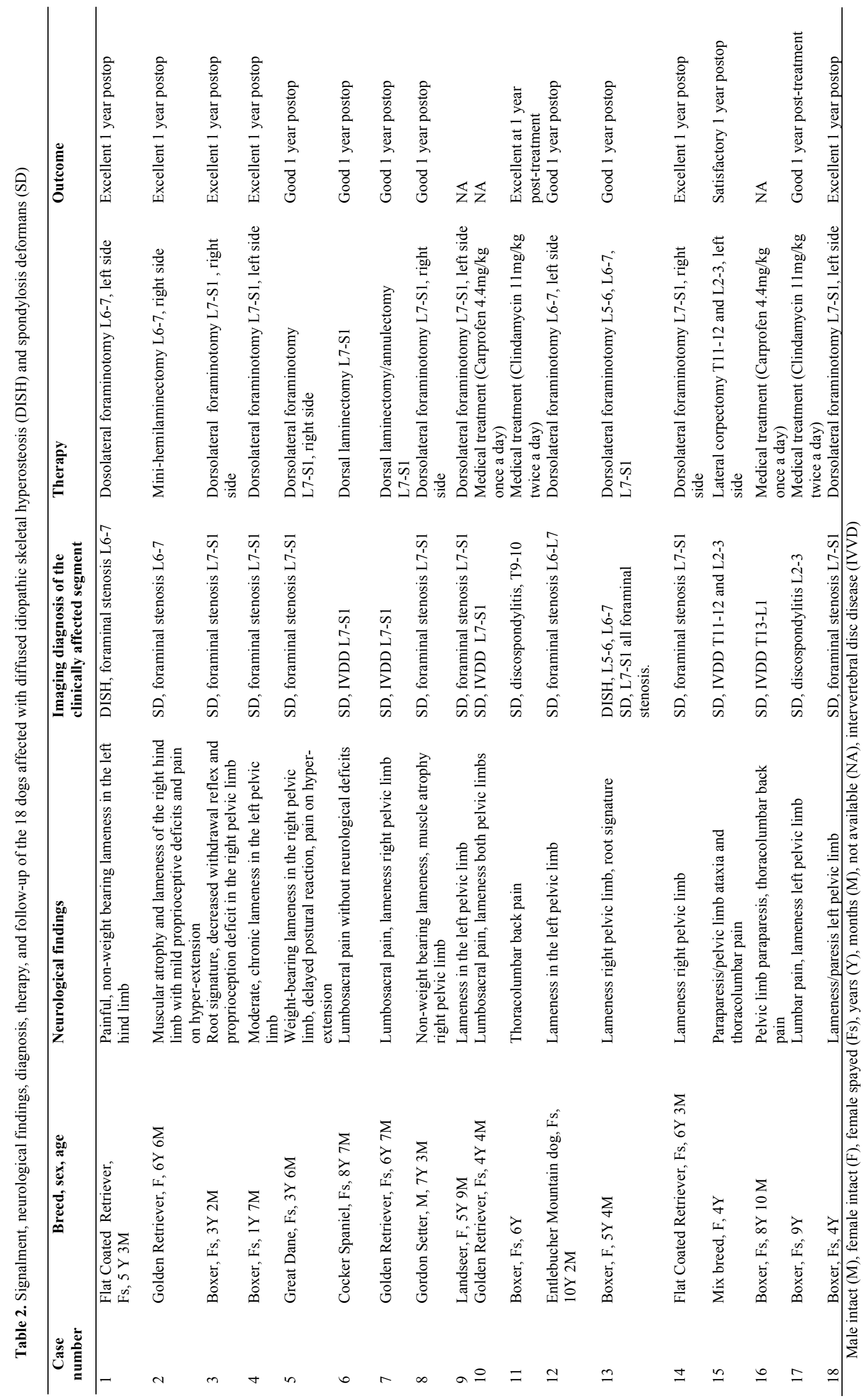




\section{Discussion}

The most important findings of this study were statistically significant differences in both the Pfirrmann grade and the SIx of new bone between vertebral segments affected with DISH and SD.

Firstly, the near normal Pfirrmann score on 'T2-weighted' images of DISH segments, confirmed the finding of the few histological human and canine studies that DISH is associated with only minor degrees of IVD degeneration (Morgan \& Stavenborn 1991; H.-J. C. Kranenburg et al. 2011; Resnick \& Niwayama 1976). In contrast, IVD degeneration is a common but not consistent finding in SD (Morgan et al. 1985; Morgan et al. 1967; Morgan et al. 1989). The Pfirrmann scale has been proven to correlate with the histological degree of disc degeneration in dogs and humans and was therefore found to be a useful tool to help in separating DISH and SD in the present investigation (Pfirrmann et al. 2001; Bergknut et al. 2011). While the Pfirrmann grade may not be essential clinically, more sensitive evaluation of the degeneration status is helpful in cases where the radiographic appearance of the intervertebral disc space is normal despite presence of new bone formations. This is illustrated in the radiographic investigation by Kranenburg et al. (2010) in which up to three reviews by different investigators were necessary until a consensus about the diagnosis of DISH was established in some of their cases.

Secondly, the signal intensity of new bone quantified by the SIx was significantly different between SD and DISH. DISH proliferations were similar to normal vertebral bone marrow on visual assessment. Here, signal behavior was characterized by a homogeneous high signal on both, 'T1- and T2weighted' sequences. This can be best explained by the presence of fat, a characteristic of normal bone marrow with a trabecular pattern. This was 
supported by the results of STIR sequences that equally suppressed fat signal in new bone of DISH and bone marrow. In contrast, the signal behavior of vertebral bone marrow and new bone formation in vertebral segments with SD was markedly different on visual assessment; was characterized by a homogenous reduction of SI on both 'T1- and T2 weighted' sequences compared to SI of the vertebral bone marrow. The reduced SI of new bone extended into the area of subchondral bone marrow and vertebral endplates in a majority of cases, reflecting bone sclerosis in SD segments. In order to quantify and to objectify these differences the SIx was created. The use of this index eliminates differences in SI that may occur between individual patients and it allows a systematic and reproducible assessment of SI.

In this population of dogs affected with DISH all animals were of medium and large breed and most of them were female. No plausible explanation for these findings can be offered and larger surveys would be necessary to show if this was just a random finding in this relatively small population of dogs.

A direct association between DISH and clinical signs was seen in two cases of the present study: bony proliferations in the region of the exit zones of the intervertebral foramen resulted in foraminal stenosis and nerve root irritation. An association between intervertebral disc herniation at sites adjacent to segments affected with DISH is suggested according to previous reports (Morgan et al. 1967; Ortega et al. 2012; Morgan et al. 1989), but remains to be proven. Clinical and experimental data in rabbits, dogs and humans support the theory that fusion of two vertebral bodies induces alterations and stresses at adjacent, mobile segments (Dekutoski et al. 1994; Eck et al. 1999; Park et al. 2004; Modic \& Ross 2007). As DISH can be regarded as a natural fusion process, similar biomechanical sequels for spinal mobility are plausible. In this context, it is interesting to note that DISH was not observed at the lumbosacral junction in the dogs of the present investigation but SD was an ubiquitous 
finding. One possible explanation is that DISH does not occur at L7-S1 because of the increased range of motion at this site compared to other areas. In addition, increased stress induced by fused segments cranially may hasten the development of degenerative changes. In contrast, this type of adjacent segment degeneration was not found in vertebral segments affected with DISH. It is possible that the rigidity between two vertebrae with DISH may protect the disc from mechanical stress and prevent it from degeneration.

Nineteen of 108 vertebral segments displayed characteristics on radiographs and MRI that did not allow separation of the two entities. Possible explanations for this include that both pathologies are present concomitantly or that these segments were imaged at different stages of one or the other disease. However, absence of a low SIx (absence of fat) suggests that these segments are more likely to be affected with SD because DISH is not associated with bone marrow changes (H.-J. C. Kranenburg et al. 2011). Follow-up scans would be necessary to answer some of these questions. Also, this result demonstrates that MRI does not allow aetiologic diagnosis of new bone proliferations in all cases.

Further limitations of the present study include the lack of a control population of asymptomatic dogs with DISH or a group of dogs with SD without signs of DISH. This would allow more accurate conclusions about the clinical significance of radiographic and MRI findings and the incidence of clinical signs in dogs with DISH and/or SD. Further limitations include the retrospective nature of this study.

In conclusion, MRI provides useful information about diagnosis and aetiology of spinal new bone proliferations in dogs. MRI allows sensitive categorization of spinal new bone into DISH and SD by providing information about the signal intensity of new bone. MRI grading of the degeneration status of the IVD facilitates establishing the diagnosis of 
DISH and/or SD without radiographic evidence of disc degeneration. However, not all abnormal vertebral segments could be assigned to one or the other disorder in the present investigation.

\section{References}

Belanger, T.A. \& Rowe, D.E., 2001. Diffuse idiopathic skeletal hyperostosis: musculoskeletal manifestations. The Journal of the American Academy of Orthopaedic Surgeons, 9(4), pp.258-267.

Benneker, L.M. et al., 2005. Correlation of radiographic and MRI parameters to morphological and biochemical assessment of intervertebral disc degeneration. European Spine Journal, 14(1), pp.27-35.

Bergknut, N. et al., 2011. Evaluation of intervertebral disk degeneration in chondrodystrophic and nonchondrodystrophic dogs by use of Pfirrmann grading of images obtained with low-field magnetic resonance imaging. American Journal of Veterinary Research, 72(7), pp.893-898.

Burnham, K.P., 2004. Multimodel inference: understanding AIC and BIC in model selection. Sociological Methods \& Research, 33(2), pp.261-304.

Cammisa, M., De Serio, A. \& Guglielmi, G., 1998. Diffuse idiopathic skeletal hyperostosis. European Journal of Radiology, 27, pp.S7-S11.

Carnier, P. et al., 2004. Prevalence of spondylosis deformans and estimates of genetic parameters for the degree of osteophytes development in italian boxer dogs. Journal of Animal Science, 82(1), pp.85-92.

Dekutoski, M.B. et al., 1994. Comparision of in in vivo and in vitro adjacent segment motion after lumbar fusion. Spine, 19(15), pp.1-7.

Eck, J.C., Humphreys, S.C. \& Hodges, S.D., 1999. Adjacent-segment degeneration after lumbar fusion: a review of clinical, biomechanical, and radiologic studies. American Journal of Orthopedics (Belle Mead, N.J.), 28(6), pp.336-340.

Eichelberg, H. \& Wurster, H., 1982. Untersuchungen zur Spondylosis deformans bei Boxern. Kleintierpraxis, 27.

Kiss, C. et al., 2002. Risk factors for diffuse idiopathic skeletal hyperostosis: a case-control study. Rheumatology (Oxford, England), 41(1), pp.27-30.

Kranenburg, H.-J.C. et al., 2011. Diffuse idiopathic skeletal hyperostosis (DISH) and spondylosis deformans in purebred dogs: A retrospective radiographic study. The Veterinary Journal, 190(2), pp.e84-e90. 
Kranenburg, H.C. et al., 2010. The dog as an animal model for DISH? European Spine Journal,19(8), pp.1325-1329.

Langeland, M. \& Lingaas, F., 1995. Spondylosis deformans in the boxer: estimates of heritability. Journal of Small Animal Practice, 36(4), pp.166-169.

Larsen, J.S. \& Selby, L.A., 1981. Spondylosis deformans in large dogs: relative risk by breed, age and sex. Journal of the American Animal Hospital Association, 17.

Levine, G.J. et al., 2006. Evaluation of the association between spondylosis deformans and clinical signs of intervertebral disk disease in dogs: 172 cases (1999-2000). Journal of the American Veterinary Medical Association, 228(1), pp.96-100.

Mata, S. et al., 1997. A controlled study of diffuse idiopathic skeletal hyperostosis. Clinical features and functional status. Medicine, 76(2), pp.104-117.

Modic, M.T. \& Ross, J.S., 2007. Lumbar degenerative disk disease. Radiology, 245(1), pp.43-61.

Morgan, J.P. \& Stavenborn, M., 1991. Disseminated idiopathic skeletal hyperostosis (DISH) in a dog. Veterinary Radiology, 32(2), pp.65-70.

Morgan, J.P., Biery, D.N. \& Newton, C.D., 1985. Spondylosis deformans. Textbook of Small Animal Orthopaedics, pp.733-738.

Morgan, J.P., Hansson, K. \& Miyabayashi, T., 1989. Spondylosis deformans in the female beagle dog: A radiographic study. Journal of Small Animal Practice, 30(8), pp.457-460.

Morgan, J.P., Ljunggren, G. \& Read, R., 1967. Spondylosis deformans (vertebral osteophytosis) in the dog. A radiographic study from England, Sweden and U.S.A. Journal of Small Animal Practice, 8(2), pp.57-66.

Olivieri, I. et al., 2007. Diffuse idiopathic skeletal hyperostosis may give the typical postural abnormalities of advanced ankylosing spondylitis. Rheumatology (Oxford, England), 46(11), pp.1709-1711.

Ortega, M. et al., 2012. Spondylosis deformans and diffuse idiopathic skeletal hyperostosis (DISH) resulting in adjacent segment disease. Veterinary Radiology \& Ultrasound, 53(2), pp.128-134.

Park, P. et al., 2004. Adjacent segment disease after lumbar or lumbosacral fusion: review of the literature. Spine, 29(17), pp.1938-1944.

Pfirrmann, C.W. et al., 2001. Magnetic resonance classification of lumbar intervertebral disc degeneration. Spine, 26(17), pp.1873-1878.

Resnick, D. \& Niwayama, G., 1976. Radiographic and pathologic features of spinal involvement in diffuse idiopathic skeletal hyperostosis (DISH). Radiology, 119(3), pp.559-568.

Rogers, J. \& Waldron, T., 2001. DISH and the monastic way of life. International Journal of Osteoarchaeology, 11(5), pp.357-365. 
Verlaan, J.-J. et al., 2011. Diffuse idiopathic skeletal hyperostosis of the cervical spine: an underestimated cause of dysphagia and airway obstruction. The Spine Journal, 11(11), pp.1058-1067.

Westerveld, L.A., Verlaan, J.J. \& Oner, F.C., 2009. Spinal fractures in patients with ankylosing spinal disorders: a systematic review of the literature on treatment, neurological status and complications. European Spine Journal, 18(2), pp.145-156.

Woodard, J.C. et al., 1985. Canine diffuse idiopathic skeletal hyperostosis. Veterinary Pathology, 22, pp.317-326. 


\section{Danksagung}

Ich möchte mich herzlich bei PD Dr. med. vet. Frank Steffen, allen Co-Autoren und den Mitarbeitern der neurologischen Abteilung bedanken für die Betreuung und Hilfe während meiner Zeit der Doktorarbeit.

Weiter danke Ich meiner Familie und meiner Freundin für Ihre Unterstützung. 


\section{Curriculum Vitae}

Togni Andrea Giovanni

von Brione/Verzasca TI, Schweiz

Geboren am 1. Januar 1980 in Locarno

1986 - $1991 \quad$ Elementari in Massagno

1991 - $1995 \quad$ Medie in Massagno

1995 - $2000 \quad$ Liceo Typus C in Lugano 2

2000 - $2006 \quad$ Studium der Veterinärmedizin an der Universität Zürich

3. Nov. 2006 Abschlussprüfung vet. med., Universität Zürich, Schweiz

Jan-Dez. 2008 Internship, Kleintierchirurgie, Vetsuisse-Fakultät, Universität Zürich

Juli 2009 - Juli 2010 Assistenzarzt, Kleintierchirurgie, Vetsuisse-Fakultät, Universität Zürich

Juli 2010 - Juli 2014 Residency ECVS, Kleintierchirurgie, Vetsuisse-Fakultät, Universität Zürich

24. Juni $2014 \quad$ Promotion 